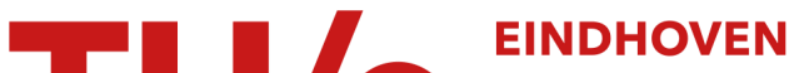 UNIVERSITY OF TECHNOLOGY
}

\section{High aspect ratio surface relief structures by photoembossing}

\section{Citation for published version (APA):}

Hermans, K., Wolf, F. K., Perelaer, J., Janssen, R. A. J., Schubert, U. S., Bastiaansen, C. W. M., \& Broer, D. J. (2007). High aspect ratio surface relief structures by photoembossing. Applied Physics Letters, 91(17), 1741031/3. [174103]. https://doi.org/10.1063/1.2799744

DOI:

10.1063/1.2799744

Document status and date:

Published: 01/01/2007

\section{Document Version:}

Publisher's PDF, also known as Version of Record (includes final page, issue and volume numbers)

\section{Please check the document version of this publication:}

- A submitted manuscript is the version of the article upon submission and before peer-review. There can be important differences between the submitted version and the official published version of record. People interested in the research are advised to contact the author for the final version of the publication, or visit the $\mathrm{DOI}$ to the publisher's website.

- The final author version and the galley proof are versions of the publication after peer review.

- The final published version features the final layout of the paper including the volume, issue and page numbers.

Link to publication

\section{General rights}

Copyright and moral rights for the publications made accessible in the public portal are retained by the authors and/or other copyright owners and it is a condition of accessing publications that users recognise and abide by the legal requirements associated with these rights.

- Users may download and print one copy of any publication from the public portal for the purpose of private study or research.

- You may not further distribute the material or use it for any profit-making activity or commercial gain

- You may freely distribute the URL identifying the publication in the public portal.

If the publication is distributed under the terms of Article 25fa of the Dutch Copyright Act, indicated by the "Taverne" license above, please follow below link for the End User Agreement:

www.tue.nl/taverne

Take down policy

If you believe that this document breaches copyright please contact us at:

openaccess@tue.nl

providing details and we will investigate your claim. 


\title{
High aspect ratio surface relief structures by photoembossing
}

\author{
Ko Hermans, ${ }^{\text {a) }}$ Florian K. Wolf, Jolke Perelaer, Rene A. J. Janssen, \\ Ulrich S. Schubert, and Cees W. M. Bastiaansen \\ Department of Chemical Engineering, Eindhoven University of Technology, 5600 MB Eindhoven, \\ The Netherlands \\ Dirk J. Broer \\ Philips Research Laboratories, High Tech Campus 4, 5656 AE Eindhoven, The Netherlands
}

(Received 20 August 2007; accepted 26 September 2007; published online 26 October 2007)

\begin{abstract}
Photoembossing is a convenient and economical process to form complex surface relief structures in polymer thin films. We have improved the aspect ratio of photoembossed microstructures by adding $t$-butyl hydroquinone (TBHQ) to the polymerization mixture. The mechanism that is proposed is based on the radical transfer principle, where TBHQ converts acrylate radicals into stable phenol radicals that at elevated temperatures act as latent initiators, thereby controlling the kinetics without changing the number of polymerization active sites. As a result, the aspect ratio can be improved with a factor of 5-7 in comparison with previously proposed similar processes. () 2007 American Institute of Physics. [DOI: 10.1063/1.2799744]
\end{abstract}

Photoembossing is a promising new technique for creating surface relief structures. ${ }^{1-4}$ This technique is based on a photopolymer that in its most simple form consists of a polymeric binder, a multifunctional monomer, and a photoinitiator. This mixture is processed from the solution to form a solid thin film on a substrate. A relief structure is created into the photopolymer by a simple two step procedure. First, a patterned ultraviolet (UV) exposure is applied to the photopolymer to create a latent image. Second, the sample is heated causing a reaction driven diffusion of reactive species to the exposed areas and the development of the surface relief structure. ${ }^{5,6}$ In a final processing step, the sample is fully polymerized by applying a flood exposure. Unlike conventional patterning techniques, such as hot embossing or photolithography, photoembossing does not require expensive moulds or contact with aggressive etching fluids or solvents. Combined with the ease of processing, photoembossing is a convenient and economical process to form complex surface relief structures in polymer thin films. A schematic representation of the photoembossing process is given in Fig. 1.

In order to expand the range of applications and to be more competitive with other technologies, it is the objective of our research to increase the aspect ratio of the surface relief structures. In current photoembossing, the aspect ratio, defined as the ratio of height and width, is typically less than $1 / 20$ for a $40 \mu \mathrm{m}$ periodic line structure. ${ }^{7,8}$

It was found that the material flux, and thus the aspect ratio, is highly affected by the polymerization kinetics and can be optimized by changing the rate of initiation via altering initiator content or light intensity. ${ }^{9}$ It is the objective of our present research to improve the aspect ratio even further. In this paper, we improved on the aspect ratio by tailoring the kinetics using the addition of $t$-butyl hydroquinone (TBHQ), which is a well-known inhibitor and/or retarder. ${ }^{10-13}$

For the photopolymer polybenzylmethacrylate $\left(M_{w}\right.$ $70 \mathrm{~kg} \mathrm{~mol}^{-1}$, Scientific Polymer Products) was used as a polymeric binder, dipentaerythritol penta-/hexa-acrylate
(Sigma Aldrich) as a multifunctional monomer, and Irgacure 819 (CIBA, Specialty Chemicals) as a photoinitiator. As a solvent, a 50/50 wt \% mixture of ethoxypropylacetate (Avocado Research Chemicals) and propyleneglycolmethyletheracetate (Aldrich) was used. To prepare the photopolymer solutions, the multifunctional monomer and the solvent were mixed in a weight ratio of $1: 2$, and the the $500 \mathrm{ppm}$ of 4-methoxyphenol present in the monomer was removed by using a silica packed inhibitor removing column (Aldrich). The monomer/solvent mixture was mixed with the polymer and photoinitiator in a weight ratio of respectively 30:10:1, and TBHQ (Aldrich) was added in different concentrations to the photopolymer solution.

The photopolymer solution was spincoated on top of cleaned glass substrates and subsequently dried at $80{ }^{\circ} \mathrm{C}$ for 20 min, resulting in dry films with a thickness of approximately $16 \mu \mathrm{m}$. Next, the samples were UV mask exposed using a line mask with a $40 \mu \mathrm{m}$ periodicity in direct contact with the sample. After exposure the mask was removed and the sample was gradually heated to a temperature of $110^{\circ} \mathrm{C}$
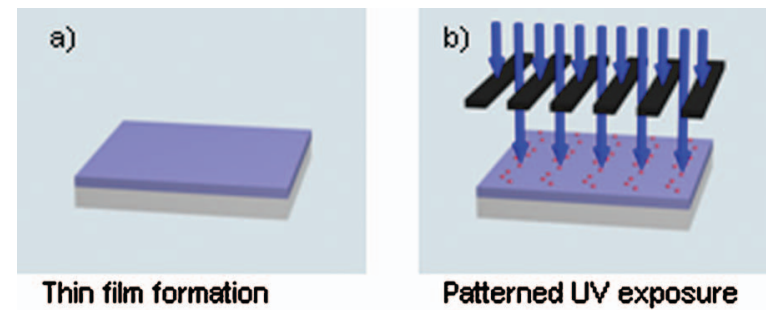

Patterned UV exposure
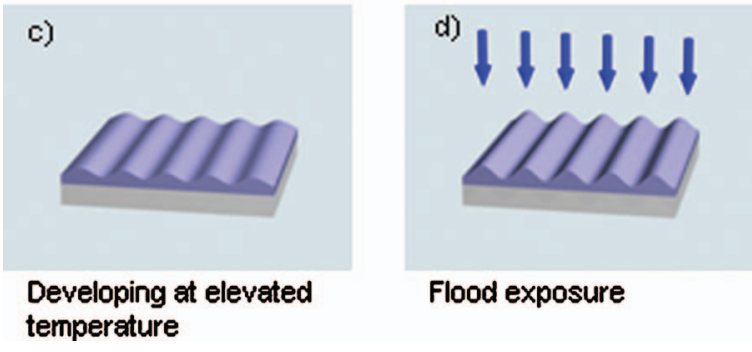

Flood exposure

\footnotetext{
${ }^{a)}$ Electronic mail: k.hermans@tue.nl
}

FIG. 1. (Color) Schematic representation of the photoembossing process. 

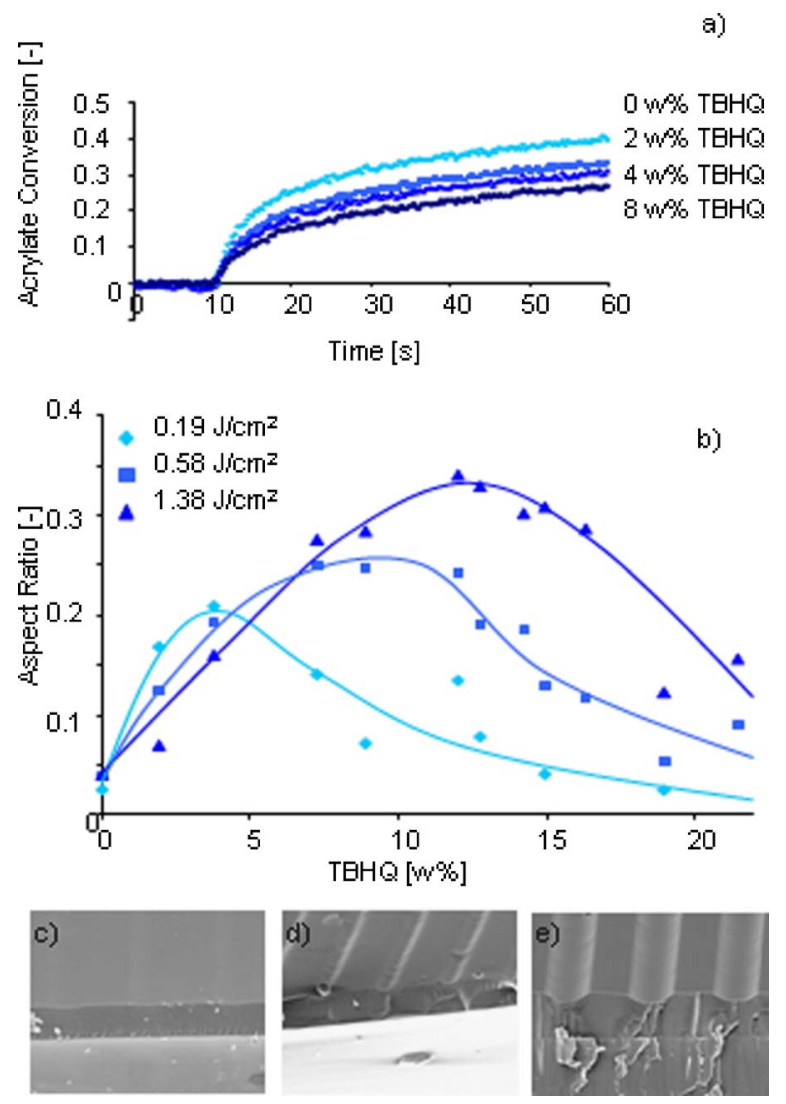

FIG. 2. (Color online) (a) Acrylate conversion upon continuous UV exposure for different amounts of TBHQ added to the photopolymer. (b) Aspect ratio as a function of amount of TBHQ added to the photopolymer for 0.19 , 0.58 , and $1.38 \mathrm{~J} / \mathrm{cm}^{2}$ mask exposure dose (line mask with pitch $=40 \mu \mathrm{m}$ ). Trend lines are added to guide the eye. Scanning electron microscopy pictures of photoembossed structures from samples with (c) $0 \mathrm{wt} \%$, (d) $4 \mathrm{wt} \%$, and (e) $20 \mathrm{wt} \%$ of TBHQ added to the photopolymer and exposed to $2.4 \mathrm{~J} / \mathrm{cm}^{2}$.

and kept for $10 \mathrm{~min}$ at this temperature before applying a flood exposure to fully polymerize the photopolymer. To prevent oxygen inhibition during exposure, development, and flood exposure, the samples were placed under a protective atmosphere by constant nitrogen blanketing.

The resulting structure heights were measured with a mechanical profilometer from Tencor Instruments (AlphaStep 200), which was equipped with a stylus with a $2 \mu \mathrm{m}$ radius and a $45^{\circ}$ tip angle.

We first studied the effect of TBHQ on the polymerization kinetics by means of real time attenuated total reflection infrared spectroscopy upon UV flood exposure of a solid photopolymer film. Different amounts of 0,2, 4, and 8 wt $\%$ TBHQ were added to the photopolymer. The photopolymerization was initiated $10 \mathrm{~s}$ after starting the measurement by continuous exposure to UV light $(\lambda=365 \mathrm{~nm}$ and $I=1.5$ $\times 10^{-3} \mathrm{~J} / \mathrm{cm}^{2}$ ). The results, which are displayed in Fig. 2(a), clearly show that adding TBHQ reduces the rate of polymerization and no induction period was found. This indicates that TBHQ behaves predominantly as a retarder in the photopolymer system upon photopolymerization.

We subsequently studied the effect of TBHQ on the aspect ratio of photoembossed structures. The results are given in Fig. 2(b). The results show that the aspect ratio increases with increasing amounts of TBHQ up to a maximum, of which the position depends on the exposure dose used during the mask exposure step. Beyond this maximum, the enDownloaded 04 Jun 2008 to 131.155.151.25. Redistribution subject
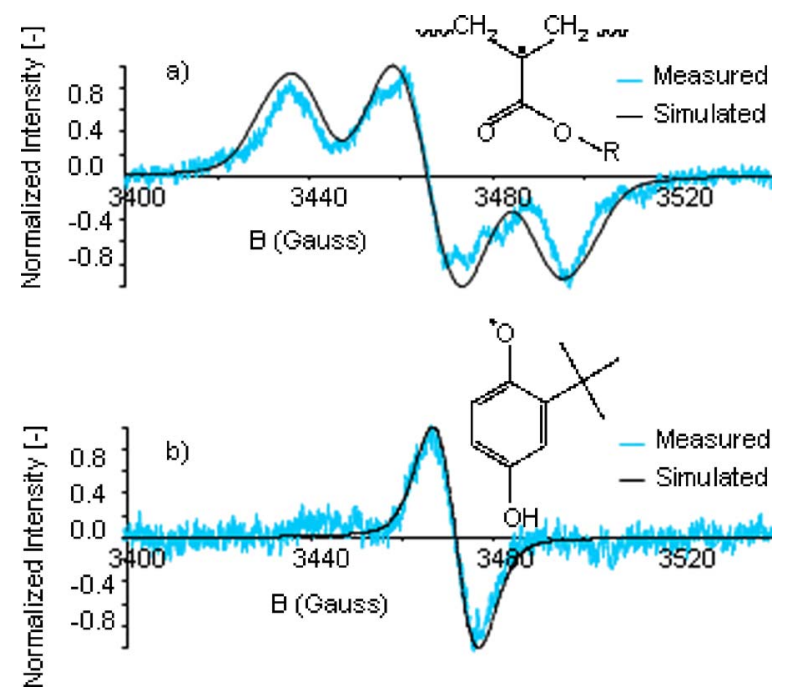

FIG. 3. (Color online) The ESR spectra upon the UV exposure of a photopolymer film with (a) $0 \mathrm{wt} \%$ TBHQ and (b) $8 \mathrm{wt} \%$ TBHQ. Both the measured and the simulated spectra are given $\left[a_{\mathrm{H}}=21.0 \mathrm{G}(2 \mathrm{H})\right]$.

hanced effect of the TBHQ diminishes again. The extent of increase in aspect ratio is further illustrated by scanning electron microscopy images, which are given in Figs. 2(c)-2(e), of samples containing different concentrations of TBHQ. Much to our surprise, the increase of the height of the structures and their aspect ratio is much larger than what can be achieved by simply reducing the polymerization rate by the reduction of light intensity or initiator concentration alone. ${ }^{14}$ This means that there must be an additional mechanism explaining the enormous effects of TBHQ, which we will try to elucidate in the following paragraphs.

In contrast to decreasing the rate of polymerization by intensity reduction, the presence of TBHQ only temporarily reduces the number of free radicals by capturing them into low-reactive species. However, these species are reactivated again during the heating step where the structures are being formed, thus increasing the concentration of initiating free radicals. Also, in the absence of TBHQ, the dominant "buried" radical species for a multifunctional acrylate are commonly found to be midchain acrylate radicals. ${ }^{15}$ Although highly reactive, these radicals have an extreme longevity which is caused by steric effects that prevent any further reactions. Upon the addition of TBHQ, highly reactive acrylate radicals are transferred to the phenolic compound, thus creating the stable radical species, acting as a latent initiator. Upon heating, the enhanced consumption of monomer leads to an increased driving force for diffusion. The formation of the stable phenolic free radical species is further supported by electron spin resonance (ESR) spectra taken from samples with 0 and 8 wt \% TBHQ upon exposure to UV light. The results, which are given in Figs. 3(a) and 3(b), show that in the absence of TBHQ, the ESR signal consists of a complex line pattern, suggesting the presence of multiple radicals or radicals in different conformations. The main contribution, however, is ascribed to a midchain acrylate radical [see inset of Fig. 3(a)], exhibiting hyperfine coupling to two of the four methylene protons, giving rise to a three-line ESR spectrum. In the presence of TBHQ, the ESR signal is clearly different. The single line spectrum fits the expected signature of a phenol radical [see inset of Fig. 3(b)] under the condition of reduced spectral resolution present in a solid polymer film. ${ }^{16}$
to AIP license or copyright; see http://apl.aip.org/apl/copyright.jsp 
When the TBHQ concentration becomes too high, the maximum aspect ratio decreases again. We believe that besides the function of latent initiator, it also contributes to the termination of the polymerization reaction. A first indication for this can be obtained from Fig. 2(a), showing that under the same conditions, a higher TBHQ concentration leads to lower end-conversion and thus smaller monomer consumption. Also, as monomer consumption in the exposed areas is the main driving force for diffusion, a reduction in end conversion thus results in less diffusion. This effect can be postponed by choosing a higher exposure dose, increasing the concentration of the initially captured reactive species. It is this balance between the initial concentration of reactive species and the end conversion, or the exposure dose and the TBHQ concentration, that influences the final aspect ratio of the photoembossed structures and explains the observations from Fig. 2(b).

In conclusion, we have shown that by adding TBHQ, the aspect ratio of photoembossed structures in a thin film can be increased with a factor of 5-7. In the absence of environmental oxygen, TBHQ behaves as a retarder in the photopolymer system and reduces the rate polymerization by converting acrylate radicals into stable phenol radicals. It is proposed that the increase in aspect ratio is predominately caused by the formation of stable radicals which can more easily reinitiate the polymerization of diffusing monomer during heat development than the persistent radicals which are formed in the absence of TBHQ.
The research is performed in the framework of a project sponsored by the Dutch Polymer Institute (DPI projects 530 and 546).

${ }^{1}$ O. V. Sakhno and T. N. Smirnova, Optik 113, 130 (2002).

${ }^{2}$ J. R. Lawrence, F. T. O'Neill, and J. T. Sheridan, Optik 112, 449 (2001).

${ }^{3}$ T. F. O'Neil, I. C. Rowsome, A. J. Carr, S. M. Daniels, M. R. Gleeson, J.

V. Kelly, J. R. Lawrence, and J. T. Sheridan, Proc. SPIE 5827, 445 (2005).

${ }^{4}$ C. de Witz and D. J. Broer, Polym. Prepr. (Am. Chem. Soc. Div. Polym. Chem.) 44, 236 (2003).

${ }^{5}$ C. M. Leewis, A. M. De Jong, L. J. van IJzendoorn, and D. J. Broer, J. Appl. Phys. 95, 4125 (2004).

${ }^{6}$ C. M. Leewis, A. M. De Jong, L. J. van IJzendoorn, and D. J. Broer, J. Appl. Phys. 95, 8352 (2004).

${ }^{7}$ N. Adams, B. de Gans, D. Kozodaev, C. Sánchez, C. W. M. Bastiaansen, D. J. Broer, and U. S. Schubert, J. Comb. Chem. 8, 184 (2006).

${ }^{8}$ K. Hermans, M. van Delden, C. W. M. Bastiaansen, and D. J. Broer (unpublished).

${ }^{9}$ C. Witz, C. Sanchez, C. W. M. Bastiaansen, and D. J. Broer, Handbook of Polymer Reaction Engineering, edited by T. Meyer and J. Keurentjes (Wiley-VCH, Weinheim, Germany, 2005), Vol. 2, Ch. 19, pp. 995-1013.

${ }^{10} \mathrm{G}$. Odian, Principles of Polymeriztion, 4th ed. (Wiley Interscience, New Jersey, 2004), Vol. 1, pp. 255-264.

${ }^{11}$ G. Moad and D. H. Solomon, The Chemistry of Free Radical Polymerization (Elsevier Science, Great Britain, 1995), Vol. 1, pp. 260-266.

${ }^{12}$ J. Brandrup and E. H. Immergut, Polymer Handbook, 4th ed. (Wiley Interscience, New York, 1999), Vol. 1, pp. II-53-II-55.

${ }^{13}$ F. Tudös and T. Foldes-Berezsnich, Prog. Polym. Sci. 14, 717 (1989).

${ }^{14}$ C. Sánchez, B.-J. de Gans, D. Kozodaev, D. Wouters, A. Alexeev, M. J. Escutti, C. Van Heesch, T. Bel, U. S. Schubert, C. W. M. Bastiaansen, and D. J. Broer, Adv. Mater. (Weinheim, Ger.) 17, 2567 (2005).

${ }^{15}$ E. Selli and C. Oliva, Macromol. Chem. Phys. 196, 4129 (1995).

${ }^{16}$ J. Zhu, W. J. Johnson, C. L. Sevilla, J. W. Herrington, and M. D. Sevilla, J. Phys. Chem. 94, 7185 (1990). 